\title{
Latent Palm Prints- an Appraisal of Concealed individualize Evidence and Its Aspect in Forensic Investigation
}

\author{
Amit Chauhan* \\ Amity Institute of Forensic Sciences, Amity University, India
}

Submission: December 04, 2017; Published: December 12, 2017

*Corresponding author: Amit Chauhan, Amity Institute of Forensic Sciences, Amity University, India, Tel: 9540067484/9968758413;

Email: amit_chauhan777@yahoo.in

\begin{abstract}
With the advancement in forensic science, the criminal felons also have adopted the new methods to commit the crime with a fundamental intention not to leave any traces at the scene of occurrence. Hence, it has been the concern of forensic jurisdiction to analyze the evidences recouped from the different aquatic environment. Evidences might be encountered in distinct form i.e. latent prints, blood stain, sweat, semen, etc. and the authorities must recognize them for further custodial procedure. These evidences inherently implement many of the individual characteristics to identify an individual after a treatment (Intensification of Palm prints/ Fingerprints). Both the, intensified palm prints and fingerprints provides the friction ridge information in form of a hidden impression over any surface. This study was carried out to get the information about the individuality from the intensified palm prints present on documents. As a study, it was observed that each intensified palm print carried the sufficient information about an individual up-to a definite level of detail. This implementation of intensified palm prints along with the examination of questioned documents could increase the potential value of evidences in court of law and put on the par above of all other evidences.
\end{abstract}

Keywords: Latent prints; Identification; Documents; Characteristics; Assessment; Forensic

\section{Introduction}

In this revolutionary phase of investigation, new techniques have overcome to the traditional techniques to provide the link between the crime and suspect to establish the conclusive identification of actual culprit of the omission. Criminal felons have an indispensable intention not to leave any traces at the scene of occurrence but are left unknowingly in form of traces, biological evidences, veiled prints etc [1]. Some of felons believe consider that evidences can be eliminate and left with no value. The felons and investigating agencies have been amazed by the numerous forms of evidences that endures perpetuated despite the duration of submersion [2,3]. The felons follow diverse types of cautions to avoid any contact with any object/surface not to leave any traces (Fingerprints, Palm prints \& Sole) by using gloves, head cap, specific dressings etc. but even after, clues are left behind unknowingly to provide their link with omission. These evidences are needed to be careful prescription and analysis to prove the identity of culprit [4].

Numerous studies i.e. identification, gender discrimination, aging etc. are carried out by the fingerprints intensification and using the information presented in form of a friction ridge impression which depends upon their qualities, nature, time and several factors [5]. The dossier represented by the friction ridge impression allows the determination that corresponding area of ridge impression either originated from the finger, palm, sole of suspect or it could have been made by someone else. Being perpetual, unique and ubiquitous by nature, these impressions have been used for over a century for identification [6]. A lot of advancement has been made in fingerprinting field i.e. biometrics, software, etc. which are helpful to identify the suspects from the ridge details among the dossier of millions of people within a few of seconds, but the palm prints are left as unidentifiable and hardly a few works exists over it. Fingerprints are encountered in partial form as if it is divided in quadrant form the core of prints/center, then the I \& III quadrant of thumb, II \& IV quadrant of index finger while in case of middle finger and ring finger the area of center in partial form and the II and IV quadrant of ring finger are encountered [7].

Palm prints are very crucial evidences which can play a vital role to identify an individual and establish a relation between the suspect and scene of occurrence/victim. Palm prints are 
encountered almost every surface e.g. documents, wall, dead body, eatable items, bottle of beverages etc. in latent form. As fingerprints are utilized for the identification of suspect similar like that Palm prints can also be. Palm prints specially the lower part (Hypothenar area) has a large area in comparison of fingerprints which are left over the object/surface, therefore, the probability of identification becomes higher from such prints [8]. In case of a sexual assault, palm prints can be recovered from the various parts of the body including the biological fluids. Sometime the biological fluids can be smudged with the secretion of victim body and identification of suspect could be ambitious, but, the palm prints could be intensified from any part of body or it could be recovered from the body of the suspect which itself prove the linkage between the victim and suspect [9]. In case of confidential documents leakage, palm prints are capable to prove the information about author, forger in form of latent palmprints which are found below the signature or writing of the author because nobody can facilitate or provide the support while writing or preparing work of art. Even during the designing of UID (Aadhar card) software, retina and fingerprints were recorded while palm prints were left unnotifiable, therefore, the utilization of this national identity of an individual can't be centralized for the aspect of investigation. Infect if the retina could be replaced by the DNA information of an individual [10].

\section{Rendezvous of Palm Prints}

Palm prints, being perpetual, unique and ubiquitous like fingerprints are encountered at numerous types of surfaces/ objects. In $90 \%$ of cases, palm prints are encountered at such surfaces which are either ignored or left in lack of investigation [11]. These prints are encountered at beverage bottles, fruits \& vegetables, eggs, magazine of firearm, handle of knife etc. In sexual assault cases, these prints are find at body parts including hand, chest, neck and private body parts etc. while in murder cases or attempt to murder or kidnapping; palm prints can be recovered from the body of the victim. Palm prints cover a large area of palmar surface and offer high probability of being identification of an individual. Since, palm prints have ridges and furrows which keeps ridge moist the sweat and left over at any surface in latent form [12]. While we are preparing or writing at any document, nobody can help to support or facilitate the movement of hand, so the latent palm prints may be encounter below the handwriting or in line (depends upon the writing habit of author). In such cases, the lower part of the hand (Hypothenar area) or thenar area and interdigital phalanges are encountered. The major creases restrict the area of palm and help to determine the individuality of suspect. The thenar area of palm have folds of skin and wrinkles which are also individualize the suspect [13].

\section{Emphasis of Palm Prints over Fingerprints}

Palm prints remains over a large area of palmar surface while fingerprints are recovered from a small part (quadrant of finger from the center of pattern) of it. Fingerprints are observed often in smudged form, overlapped conditions and provide less chances to identify the suspect. The major creases of palm prints give clue about the area of impressions. The intensity of palm prints pattern states about its ridge configuration. The ridge counting is prompted between the number present of tri-radius of palm print. The ridge count is carried out along a straight line which connects the both tri-radial points [14]. The ridge counts exclude the formation of tri-radius and follow the same principle as applied in the counting of fingerprints.

Now a day, atd angle measurement is the most widely used method that is based on the angle which is formed by lines drawn from the digital tri-radius to the axial tri-radius and from tri-radius to digital tri-radius. It is observed that the more distal position of tri-radius, the larger the atd. angle. Another proposed method for determining the position of the axial tri-radius uses the ratio between the palm length and the distance between the axial tri-radius and wrist crease $[15,16]$. This distance is measured between the most distal wrist crease and the most proximal crease of third digit. Along with this measurement, the distance between the axial tri-radius and the distal wrist crease is also measured and often expressed in form of percentage of the length of palm print.

\section{Interest in Investigation}

Palm print identification is ubiquitous and most extensively used technique in automatic personal identification based on its biostatistics. The utmost features of palm print and fingerprints are similar. Hence, palm prints are ubiquitous, perpetual and unique that don't change throughout the life and impossible to stimulate [17]. Since palm prints have larger area of palmar surface, therefore, the minutiae details are easily obtained. The palm prints comprise other identical features such as main palmar flexion creases, tri-radius, phalanges area etc. not with standing its uniqueness but also its stableness. Now day, palm prints have become the interested research field for medical practitioner. Recently, in last decade the researchers have found more than 50 diseases by using the palmprint [18]. These diseases include the gene genetic diseases, multi gene genetic disease, chromosome disease etc. For instance, abundant material has been accumulated in case-controlstudies on acyesis and schizophrenia palm print characteristics. Examination for dermatoglyphic disorderhas become a routine in diagnosis of abnormalities in chromosome number and structure.

\section{Need of Amelioration in Digital Design}

We are facilitated with advance technology in fingerprints which helps in identifying the suspect from many dossiers such as automated finger print identification system while in area of palm prints, this facility is lacking. Now a day, biometric system has replaced the traditional methods in which the information of fingerprints is stored. We have not facilitated by any software in the direction of identification from palm prints. Recently, the recognition of disease from the palm prints attracted the attention of researchers towards it. Since, no palmprints 
database was present, therefore, researchers are preparing it for use as an index to describe medical disorder. As many of research papers have shown that palm prints differ with different geological position, gender, nationality and age etc. which can be used for outstanding results in investigation to identify and individual. With the development of biology techniques, pattern recognition, neural networks and computer technique, we can build a large palm print reference database and form expert systems with study function. Much progress will be made in the fields linking palm print and heredity, palm print and disease, palm print and intelligence, palm print and growth and palm print identification.

\section{Conclusion}

Certainly, the fingerprints techniques are more advanced used for identification purpose. Yet with the rapid advancement in technology of identification and biological research, the palm prints have become an interested field among researchers. A few of techniques with some modification can be used for palm prints research/ investigation. At present, the automation is very low in palm prints and most of the work is done manually that makes computation complex, inaccurate and slow. Computation of most statistics on palm prints still use ordinary methods such as percentage, mean average, standard deviation, $t$ distributed test and X2test. Many up to date methods such as multi-variate analysis, regression analysis, and cluster analysis have been seldom used. Therefore, a broad dossier of palm print is required for establishing analysis methods, determining disease, gender discriminating, identification of races etc. that could be present as a perfect expert system with study function. This system will facilitate the investigators to minimize the number of suspects within a few of seconds and nab them.

\section{References}

1. R Pallotta, G Carlone, A Petrucci, Chiarelli F (1989) Dermatoglyphics in von Recklinghausen Neurofibromatosis. American Jornal of Medical Genetics 34(2): 233-236.

2. T Reed (1991) Hypothesis: association of the critical region of trisomy 18 and 18q2-syndrome with dermatoglyphic findingsand a growth suppressor (deleted in colon cancer) locus. Clinical Genetics 39(5): 391-395.

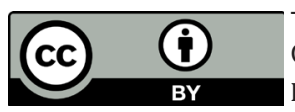

This work is licensed under Creative Commons Attribution 4.0 License DOI: $10.19080 / J F S C I .2017 .06 .555696$
3. L de Andres Basauti, L Barneo, J Carulla (1975) Genetic Factors in Breast Cancer, Oncology 32(1): 27-33.

4. HR Bierman, MR Faith, ME Stewart (1988) Digital Dermatoglyphics in Mammary Cancer, Cancer Investigation 6(1): 15-27.

5. MH Seltzer, CC Plato, KM Fox (1990) Dermatoglyphics in the Identification ofWomenEitherWith or at Risk for BreastCancer, American Jornal of Medical Genetics 37(4): 482-488.

6. M Ciovirnache, L Dumitriu, I Mogos (1986) Dermatoglyphics in Thyroid Cancer, Endocrinology 24(3): 171-183.

7. M Ciovirnache, D Ioanitiu, B Ionescu, Dumitrache C, Milea E, et al. (1986) Dermatoglyphics in the Virilizing Polycystic Ovary Syndrome. Endocrinology 24(2): 87-96.

8. Sam NM, Rema P, Nair BV (2014) Sex Determination Using Fingerprint Ridge Density In South Indian Population. Journal of Indian Academy of Forensic Medicine 36(4): 381-386.

9. Acree MA (1999) Is there a gender difference in fingerprint ridge density? Forensic science international 102(1): 35-44.

10. Khadri Sayed Yunus, Goudar ES, KhadriSayeda Yasmeen (2013) A study of fingerprint pattern and gender distribution of fingerprint in and around Bijapur, Al Ameen J Medical Sci 6(4): 328-321.

11. Wadhwa Ravi, Kaur Maninder, Singh KVP (2013) Age and gender determination from fingerprint Using RVA and Dct coefficients. IOSR Journal of Engeenering 3(8): 05-09.

12. Chauhan Amit, Singh Jyoti, Kushwaha KP Singh (2015) An Evaluation: Sexing from the Ridge density of Latent Palm prints of North Indian Population. Research Journal of Recent Sciences 4: 73-75.

13. Moore RT (1989) An analysis of ridge-to-ridge distance on fingerprints. J Forensic Ident 39: 231-38.

14. Agnihotri Anil Kumar, JowaheerVandna, AllockAnishta (2012) An analysis of fingerprint ridge density in Indo-Mauritian population and its application to gender determination. Med Sci law 52(3): 143-147.

15. Gungadin Sudesh (2007) Sex determination from fingerprint ridge density. Internet Journal of medical update 2(2): 4-7.

16. Krishan K, Kanchan Tanuj, NgangomChitrabala (2013) A study of sex differences in fingerprint ridge density in a North Indian young adult population. J Forensic Leg Med 20: 217-22.

17. Nithin MD, Balaraj BM, Manjunatha B, Mestri SC (2009) Study of fingerprint classification and their gender distribution among South Indian population. Journal of Forensic and Legal Medicine, Vol. 16(8): 460-463.

18. Kumar L, Agarwal S, Garg R, Pratap A, Mishra VK (2013) Gender Determination Using Fingerprints In the Region of Uttarakhand. Journal of Indian Academy of Forensic Medicine 35(4): 308-311.

\section{Your next submission with Juniper Publishers} will reach you the below assets

- Quality Editorial service

- Swift Peer Review

- Reprints availability

- E-prints Service

- Manuscript Podcast for convenient understanding

- Global attainment for your research

- Manuscript accessibility in different formats

( Pdf, E-pub, Full Text, Audio)

- Unceasing customer service

Track the below URL for one-step submission

https://juniperpublishers.com/online-submission. 